\title{
Main stages of effective transport management system modernization in Russian agglomerations
}

\author{
Vladimir Schwetsov ${ }^{1}$, Andrey Burmistrov ${ }^{2, *}$ and Vsevolod Morozov ${ }^{1}$ \\ ${ }^{1} \ll \mathrm{A}+\mathrm{S}$ Transproekt» LLC, Russia \\ ${ }^{2}$ Peter the Great St.Petersburg Polytechnic University, Polytechnicheskaya, 29, 195251, \\ St. Petersburg, Russia
}

\begin{abstract}
This article presents main problems typical for the transport management system in Russia. Characteristics of the barriers hampering the infrastructure projects implementation are described; possibilities for overcoming these barriers are indicated. An approach is proposed for effective modernization of transport management systems, including such components as formation of a 'common language', use of 'systems laws' and system engineering methods. The importance of the first stage including comprehension and formulation of shared values by all participants has been emphasized. The necessity of consistent coordination of the participants' interests in the transport system development is presented: from the definition of shared values to shared goals and to the general conceptual project guaranteeing achievement of these goals.
\end{abstract}

\section{Introduction}

Since the beginning of the 2000 s, we have all been witnesses and participants in the process of forming of a new technological order, the basis of which is the widespread introduction of the information technologies and emerging new management methods for all industries, including transportation.

The ubiquitous appearance of the Internet facilities should reach its peak of development in the nearest future. At the same time, each facility becomes an object of remote control and is connected with various other things (Car2X, Car2Car), and also such phenomenon as 'uberization' of economics, when a single information space makes a considerable number of intermediary organizations unnecessary, is developing. We should note that this process contributes to a closer interpenetration of technologies in related industries - transport and communications. Thus, the preliminary specifications imply that 5G telecommunications infrastructure should support at least 1 million connected devices per square kilometer, including vehicles, parking slots and traffic lights.

The emergence of new technologies that lead to a change in the technological structure requires application of new approaches and changes in the existing methods of creating and

\footnotetext{
*Corresponding author: isar@mail.ru
} 
modernizing transport management systems. The most important issue in improving any system is definition of goals and establishment of a management system for it.

\section{Materials and methods}

Nowadays the pending task in Russia is modernization of the system of transport management in agglomerations. This task has not been solved for the last 30 years in Russia, but now the urgency of this decision is recognized at the federal level by adopting the Priority Project "Safe and Qualitative Roads" (SQR Project, see [1]) which will last until 2025 and covers 36 Russian agglomerations with population of more than 500 thousand people. This project was launched in November 2016 and its assumed funding allocation is 540 billion rubles.

Changes are inevitable; the only question is how to make them the least painful and most useful for the system as a whole. For this, let us consider the difficulties encountered in reality by any concepts and plans, as well as the possibilities for overcoming them.

In general, foreign experts identify 4 types of barriers in implementation of infrastructure projects:

- Technological barriers;

- Political and cultural barriers;

- Legal and institutional barriers;

- Financial barriers [2].

Let us consider these barriers in more detail and analyze how they relate to Russian reality. Technological barriers, in our opinion, have been overcome in almost all directions of the transport infrastructure development. In fact, we can say that "technologies" have surpassed a person, and their application and further development is limited by the same barriers as the development of the entire system as a whole. Such migration is caused precisely by digitalization of industries - digital technologies have already passed to another qualitative state, when they are not an obstacle to the creation of systems, but an integral part of them.

Political and cultural barriers are among the most difficult ones, but as the successful experience of introducing the idea of collecting fare for motorways demonstrates, despite all skepticism, or a successful example of the introduction of paid parking lots in Moscow, it can be said with certainty that these barriers are completely overcomable, although not everywhere with the same speed. At the same time, in a number of cases, these barriers are almost impossible to overcome, since a new technological structure can leave a significant part of the population without work. This is due to the fact that the emergence of automatic vehicles, together with increased security, will inevitably lead to a problem - reduction in the number of jobs not only in the transport sector (drivers, mechanics), but also in its servicing branches - banking, insurance, services (refueling stations, maintenance operation, cafes). No one knows yet how to solve this problem. Legal and institutional barriers have been largely recognized and, according to our information, the most persistent efforts are made towards modernization of the legislation in the field of transport management. In particular, Federal Law No. 456-FZ of December 29, 2014 amended the Town-Planning Code to establish the requirements for development of Integrated Transport Infrastructure Development Programs (ITIDPs) for settlements and urban districts. The regulation of ITDPs was established a little later with the adoption of Decree of the Government of the Russian Federation No. 1440 of December 25, 2015. Also the Order of the Ministry of Transport of Russia No. 43 of March 17, 2015 "On Approval of the Rules for the Preparation of Road Traffic Projects and Traffic Circuits" regulating the development of relevant documents was approved. Of course, there is still a huge layer of unresolved problems related specifically to the new technologies, first of all, the delegation 
of responsibilities and risks (who is responsible for the accident if it is caused by an autonomous vehicle - owner or manufacturer? Who should be saved in case of an imminent accident - pedestrian or passenger?). However, these problems are gradually getting resolved (see [3], [10]) and its consideration is beyond the scope of this article.

Financial barriers are perhaps the most relevant for Russian cities and agglomerations. First, when using existing tools, more resources should be given to the planning stages, as this will significantly reduce costs during implementation phase (this will be discussed below). Of course, an important component is control over spending of allocated funds.

In addition, two sources of funding are currently available for financing transport development projects for cities and agglomerations:

- Budgetary funds which depend on a number of factors, primarily on the development of the region's economy;

- Extrabudgetary, first of all, investment funds.

One can say that we are seeing "a series of public-private partnership projects" in Russia, primarily in the field of infrastructure projects. There are a number of organizations and projects aimed at investing in new roads on the basis of charging, new rail transport systems, transport and transfer nodes, automated traffic control systems and other "smart and safe cities". At SPIEF-2017, several similar agreements were signed, including agreement on construction of a latitudinal highway with a bridge across the Neva in the alignment of Fayansovaya and Zolnaya streets and agreement on construction of toll railway crossings. The number of such projects is increasing every year.

However, in Russia, despite a number of positive trends (first of all, this is the growth of attention to transport issues), the following problems remain:

- A number of decisions are made on the basis of the borrowed foreign experience without taking into account local specifics;

- The decisions (arrangements) taken are repeatedly changed at the implementation stage;

- All programs and strategies are divided into local activities for specific areas of work;

- Opportunities of new technologies are not used in full, and the upcoming future requires a response;

- The developed transport models (decision-making support systems for the managers of territories) are used only in $40-60 \%$ of cases, and in other cases the position "this is a pointless theory, and we are practitioners" is taken.

In addition to concrete examples, where resources are not used in the most effective way, a number of imbalances can be formulated. Without understanding and overcoming them, negative factors will only intensify. In our opinion, the most common and critical imbalances of the transport management system in Russia are:

1. Between short-term and long-term goals. For whom do we live, for ourselves or for the future generations? Transport infrastructure and land use is clearly not a matter of one day, one year or one cycle. Although, formally, Russia has been moving towards sustainable development for 20 years, which implies only meeting the needs of the present generation without threatening the needs of future generations (on April 1, 1996, the President of the Russian Federation signed Decree No. 440 approving the Concept of the Russian Federation's Transition to Sustainable Development), but in practice, development is very different, especially in cities.

2. Imbalance between satisfaction of needs of various interest groups. Different groups are the parties involved (so-called "stakeholders") in the transport system, for example, residents and developers or the state and investors, and various departments in the management system, for example, the Ministry of Transport and the Ministry of Finance.

3. Imbalance between the implementation of individual activities and the improvement of the system as a whole. It is very difficult to develop the system as a whole, combining the activities in separate areas (bus lanes, automated traffic control systems, bicycle 
infrastructure, traffic safety, etc.), when the system as a whole is not clearly formulated and is often very vague. This can be the subject of many articles on the results of monitoring the development of general planning projects, projects for the development of transport infrastructure, integrated transport schemes and similar projects.

These imbalances are key constraints. To achieve improvement in a complex task, it is necessary to rely on scientifically based technology, which is based on clear definitions, principles of system development, general objectives and technology of work of all participants. This will allow, among other things, increasing the return on investment.

\section{Results}

To meet the new challenge of "Building an effective transport management system in Russian agglomerations," we propose the following:

1. Forming a "common language". For example, there is no definition of the term "agglomeration" in the Priority Project of SQR. To begin the discussion, we will offer our working (non-final) definition of this term: "The urban agglomeration is a territory with stable transport and cultural connections that dynamically change depending on the level of development of a particular transport infrastructure".

Also, we need to fix other definitions. For example, what a "transport management system" and "effective transport management" are. And perhaps, we should consider not "transport management", but management of "transport mobility". (Transport mobility is the process of safe, comfortable, fast, affordable and cost-effective movement of a person or a group of people using one or more modes of transport (D. Kogan, Ph.D., assistant professor of the department "Technospheric Security", MADI). see [4]. The authors' note this definition concerns only passenger transportation and needs to be modified in order to take into account needs of the population and enterprises in not only passenger but also cargo transportation. Realizing transport mobility in general sense, as a tool to meet the needs of the population, organizations, enterprises, public authorities, armed forces, special services, etc.).

2. Use of "systems laws", in particular, the following: "correction of errors at each next stage of the life cycle is several times more expensive than the previous one." To assess the economic effectiveness of this approach, it is useful to draw on the following information.

According to INCOSE (The International Council on Systems Engineering (INCOSE) is a not-for-profit membership organization founded to develop and disseminate the interdisciplinary principles and practices that enable the realization of successful systems. http://www.incose.org/about), $8 \%$ of the costs of implementing system engineering give a gain of $20 \%$ of the cost of projects, and $50 \%$ increase in the likelihood of completion the project on time. This is achieved through the introduction of a common language describing the project and a conscious shift of effort to the early stages of the project, where the price of an error is exponentially smaller (Table 1 ):

Table 1. The cost of correcting errors at different stages of the life cycle of complex systems (according to INCOSE).

\begin{tabular}{|c|c|}
\hline The stage of error detection & Error cost factor \\
\hline Purpose & x 1 (unit of reference) \\
\hline Design (development) & x 5 \\
\hline $\begin{array}{c}\text { Creation (production / manufacturing, } \\
\text { construction, etc.) }\end{array}$ & x 12 \\
\hline Clearing for operation & x 40 \\
\hline Functioning (use, application) & x 250 \\
\hline
\end{tabular}


This rule is illustrated in the figure where the horizontal axis indicates the stages of the system life cycle, and the vertical axis - the cost of correcting errors.

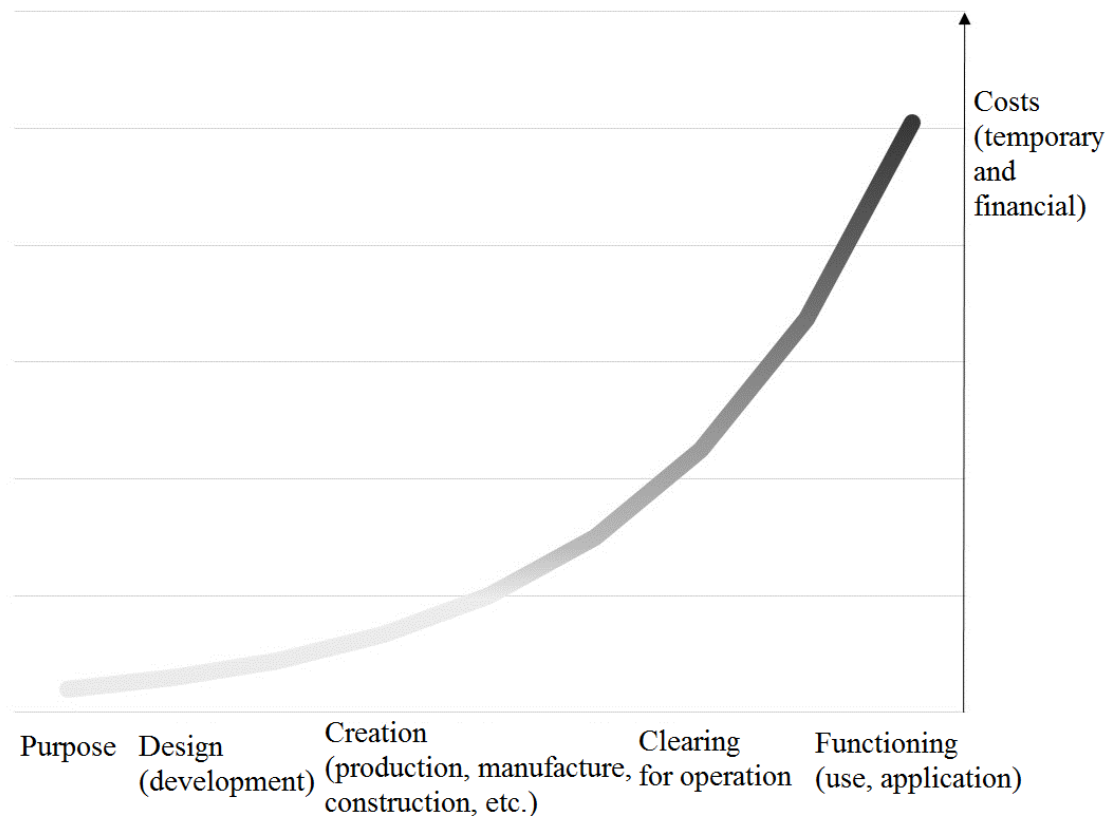

Fig. 1. Dependence of error correction cost on the stage of the system life cycle.

In other words, investments in the initial stages of the system creation are repeatedly paid off by saving in the subsequent stages - in particular, by reducing the number of changes to the already constructed facilities, reducing the commissioning (clearing for operation) time, etc.

Since the state and society are already at the stage of using the existing management system which is already functioning, a new stage (its modernization) is required to begin with formation of its shared values and concept. This is the first and most important stage in the development of an effective management system.

3. Use of the system engineering technologies and standards, presented, in particular, in the international standard ISO 15288 [5], embodied in the concept of sustainable development of the United Nations, etc. (see, for example, [6])

According to this technology, creation or modification (modernization) of transport management systems (transport mobility) in agglomerations must go through the stages indicated in Table 1, the key stage is the first stage of the "Purpose" (pre-project stage), the most important stages of which are the following:

1. Requirements definition (definition of goals).

2. Development of the system concept (ways of meeting the requirements).

\section{Discussion}

We will dwell in more detail at the most important stage - developing requirements for the system being created. The most important task at this stage is coordination of goals of the main or all involved parties. This kind of coordination is a necessary condition for overcoming the system imbalances mentioned above and ensures success of the system as a whole. 
It should be noted that all the transport planning and design guidelines suggest that the key to success is the availability of agreements among all participants in the process before starting its implementation $[7,8]$. The balance of interests is the first and vitally necessary condition for development.

Since the interests of different parties are different, and in order to achieve common success it is necessary to achieve the balance of interests, then a logical question arises around the idea that will be agreed upon and what will be common for all. And here we inevitably come to the necessity of using such a concept as "shared values", in particular, the values of "sustainable development", which became the guiding principle of the UN (the concept of sustainable development ... has become the guiding principle for long-term global development. Sustainable development involves achieving three fundamental goals: economic and social progress and environmental protection [9]).

The basic value shared by almost all people of our planet is life and its reproduction. Reproduction of life consists of reproduction of the actual population (in a traditional society this function is performed by such a social institution as the family), and the reproduction of production means which can be designated by the term "economy", or, ultimately simplifying, "business".

It turns out that in the very basis we have the population and the economy (enterprises, investors, etc.) as the basic values of any territory that mutually influence and support each other. The opportunities to solve transport problems of the territory, which are reflected in the programs of transport development, but not always observed in reality, should be considered from this prospect.

The issues of sustainable development, including the development of sustainable transport systems are very important for Russia. The following values important for the population must be taken into account in the transport planning projects of the territories: health, prosperity / abundance, personal development opportunities (measured through the amount of free time), security and much more. For transport engineers, this means that projects and activities for the development of transport infrastructure should be evaluated and ranked according to the system of indicators that corresponds to these values.

Reaching mutual understanding on values, especially so that it becomes the basis for system designing, is very difficult for different stakeholders. Therefore, we can propose a gradual approach to the formation of common values. For example, first determine the general list of stakeholders and the way they are represented in the development of requirements. Then agree on common values at the level of concepts, for example, by forming their list: "health", "safety", "preservation of the environment", etc. Then go on to the definition of indicators that will measure the level of achievement of these values. And further, having agreed on the indicators themselves, agree on the values of these indicators the desired, the maximum permissible, etc., as well as the deadlines for their achievement. This is how the transition from values to goals occurs.

As an example, the following simplified system of indicators for the stakeholder "Population" (Family and People, Table 2) can be given.

Table 2. Values and indicators for the interested party "Population".

\begin{tabular}{|c|c|}
\hline Value & Indicator \\
\hline $\begin{array}{c}\text { Health (formulated as "Ecological } \\
\text { compatibility of the transport system") }\end{array}$ & $\begin{array}{c}\bullet \text { The volume of CO2 emissions } \\
\bullet \quad \ldots\end{array}$ \\
\hline Safety & $\begin{array}{c}\text { The number of accidents per 1,000 people } \\
\text { Sree time }\end{array}$ \\
\hline $\begin{array}{c}\bullet \quad \text { Time for the implementation of basic } \\
\text { correspondence on various modes of transport } \\
\text { (individual and public) }\end{array}$ \\
\hline
\end{tabular}




\begin{tabular}{|c|c|}
\hline & $\begin{array}{c}\text { Delays in the nodes of the transport network } \\
\text { - Waiting time for public transport... }\end{array}$ \\
\hline $\begin{array}{c}\text { Prosperity / abundance (as the } \\
\text { productivity of labor, which is affected by } \\
\text { the time spent on commuting, the } \\
\begin{array}{c}\text { attractiveness of the territory where } \\
\text { people live and work, etc.) }\end{array}\end{array}$ & $\begin{array}{c}- \text { The level of income per person in a given } \\
\text { territory, }\end{array}$ \\
$\begin{array}{c}\text { - Income growth index, } \\
\text { groups expressed in rubles. }\end{array}$ \\
\hline
\end{tabular}

Similarly, we can propose a system of indicators for "business". For any commercial organization, the basic value is profit (modern concepts on social responsibility of business work only in conditions of very strict public control, which is confirmed by numerous disputes related to the use of child labor, environmental pollution, etc.; in the countries of the "third" world, where companies positioning themselves as socially responsible in developed countries operate). The profit is affected by many factors, including labor productivity, cost reduction, investment success. For the transport engineer these properties are transformed into the following system of indicators (Table 3):

Table 3. Values and indicators for the stakeholder "Business".

\begin{tabular}{|c|c|}
\hline Value & Indicator \\
\hline $\begin{array}{l}\text { Labour productivity: } \\
\text { - Employee health (formulated as } \\
\text { "Ecological compatibility of the } \\
\text { transport system") } \\
\text { - Labour safety } \\
\text { - Reduction of employee time losses } \\
\text { - ... }\end{array}$ & $\begin{array}{l}\text { The same indicators as for "Population": } \\
\text { - The volume of } \mathrm{CO} 2 \text { emissions } \\
\text { - The number of accidents per } 1,000 \text { people, etc. } \\
\text { - Time for the implementation of basic } \\
\text { correspondence on various modes of transport } \\
\text { (individual and public) } \\
\text { - ... }\end{array}$ \\
\hline $\begin{array}{l}\begin{array}{l}\text { Reduction of costs } \\
\text { enterprises) }\end{array} \\
\text { (for operating } \\
\end{array}$ & $\begin{array}{l}\text { - Freight transportation time } \\
\text { - Freight transportation costs } \\
\text { - } \quad \ldots\end{array}$ \\
\hline $\begin{array}{l}\text { Success of investments in the creation of } \\
\text { industries, including: good transport } \\
\text { accessibility for personnel }\end{array}$ & $\begin{array}{l}\text { - Number of available transport types } \\
\text { - Number of parking lots } \\
\text { - } \quad \text {.. }\end{array}$ \\
\hline etc. & \\
\hline
\end{tabular}

\section{Conclusions}

Thus, by agreeing on shared values and their key properties, we get a system of indicators that allows us to formulate a common image of the future, and which enables selection and ranking of specific measures for the transport infrastructure development.

Undoubtedly, this is not an exhaustive list of values and indicators, it is just an illustration of an approach that allows us to systematically and adequately look at the goals and objectives of transport planning as one of the stages in the development of an effective system of transport management, also for agglomerations. We will not dwell on this and the subsequent stages of a management system development. There are many books about the importance of this and other stages, about the technologies for their implementation. However, in all of them it is stated that first you need to determine the purpose - which city, region, country do you see in the future? Without having an ultimate goal, it is impossible to make a plan for its achieving. That is why we focus on the first stage of the system, in particular on its goals (values of indicators), which logically follow from values.

In conclusion, we emphasize the following:

1. It is necessary to use the chance to make a leap in the development of transport systems of all large agglomerations within the framework of the Priority Project "Safe and 
Qualitative Roads". The most remarkable thing about this project is that for the first time in the modern history of Russia, the reconstruction of roads and infrastructure is clearly linked to the traffic flow management, regulatory base and intellectual services for the population. In order to ensure the successful implementation of this project, the SQR also develops guidelines such as the Methodological Recommendations for Developing Programs for the Comprehensive Development of the Transport Infrastructure of the Major Urban Areas within the Priority Strategic Development direction in the Russian Federation "Safe and Qualitative Roads", Methodological Recommendations for the Preparation of the Program Passport, etc. For the first time in the last 25 years, it is envisaged to implement such a large-scale integrated project that provides development of both theoretical foundations and practical actions for their implementation. It is necessary to use this opportunity in the best way.

2. Financing for the transport management systems modernization in the Russian agglomerations and for the transport complexes management of other territories can be found. These are not only budgetary funds, but also the means that can be attracted under public-private partnership projects, as well as the savings made through the more efficient use of available resources (see next paragraph).

3. A key role in any endeavor is to agree on the interests of the participants, based on which the goals of the systems being created are defined. For this, shared values must be developed and the goals and concept of the system should be developed on its basis. This is the first and most important stage, the time and resources for which are usually in lack. At the same time, investments in the development of goals and concepts are repeatedly repaid by reducing the total cost of the system development and its functioning. By investing time and other resources in the concept development, in system design, in analysis and planning, one can achieve faster and more successful creation, better functioning, lower total cost of systems creating and operating.

\section{References}

1. Passport of the priority project "Safe and qualitative roads" (2016) http://government.ru/media/files/5EgAG7vBB8Y9iKqkhPBaGzh7dAml5Hhz.pdf

2. Procedures for Recommending Optimal Sustainable Planning of European City Transport Systems, Decision Makers' Guidebook (2003)

3. Prospects for the introduction of autonomous vehicles. Thematic review of the Association of Transport Engineers: Prospective Mobility and Future Cars (Ltd "Publishing and printing company «COSTA», SPb, 2017)

4. D. Kogan, Automobile transport 1, 32-37 (2016) http://ecomadi.ru/sites/default/files/32-37.pdf

5. Russian Standard GOST R ISO IEC 15288-2008

6. R. Ackoff, J. Magidson, H. Addison, Idealized design: How to prevent tomorrow's crisis today. Creating a future organization (Balance Business Books, Dnepropetrovsk 2007)

7. URL : http://mirror.unhabitat.org/pmss/getElectronicVersion.aspx?nr=3285\&alt=1

8. HiTrans, Best practice guide 2. Public transport - Planning the networks (2005) www.civitas.no/assets/hitrans2publictransportplanningthe-networks.pdf

9. URL : http://www.un.org/en/ga/president/65/issues/sustdev.shtml (2018)

10. V.V. Gloukhov, I.V. Ilin, V.I. Koposov, A.I. Levina, Asian Social Science 10(24), 209-216 (2014) 